\title{
Efficient Consumer Response (ECR) Principles and Their Application in Retail Trade Enterprises in Latvia
}

\section{Rosita Zvirgzdina, Iveta Liniṇa}

Business University Turiba, Graudu 68, Riga LV 1058, Latvia

\section{Velga Vēvere}

The University College of Economics and Culture, Lomonosova 1, corp. 5, Riga LV 1019, Latvia

$\Gamma$ Crossef $h t t p: / / d x . d o i . o r g / 10.5755 / j 01 . e i s .0 .9 .12812$

The sector of the retail trade has always played a significant role in the Latvian economics. The basis for the retail trade is the satisfaction of consumers' needs and the formation of the long-term relationship. To retain the existing consumers and to attract the new buyers, one of the fundamental tasks is to create the according assortment. The Efficient Consumer Response presupposes not only the new approach in creating the assortment, but also influences all business processes in the enterprise and significantly raises the level of assortment. The purpose of the present study is to analyze the level of the ECR application in the retail enterprises in Latvia. Therefore, there were set the following tasks: a) to characterize the retail trade tendencies in Latvia; b) to research the principles of assortment formation. The research methods applied were the expert interviews and consumers' survey. The key result of the research was: the ECR implementation helps to form the assortment of the retail trade enterprises in more responsive to consumers" needs way.

KEYWORDS: ECR, retail trade, assortment, consumers' needs, product category management.

Private consumption is one of the corner stones of the economic growth. Private consumption is a realm that raises Latvia above the average rate of the gross domestic product increase in the EU. Until the middle of 2007, the retail trade in Latvia in comparison with other branches of national economics was developing dynamically. In 2009 the trade sector overall constituted $13.8 \%$ of the GDP (in actual prices). For many several it was one of the major factors of the GDP. Largely it was because there was a tendency to put in order this sector by the state. The retail trade moved from market places, sport halls and sheds to shops and shopping malls. However, during the world economic crisis, the retail trade was one of the industries that experienced the largest drop. The total turnover of the retail trade enterprises in comparable prices in 2009 decreased by $28 \%$ in comparison with 2008 . The turnover of the food products retail trade decreased for $20.9 \%$, at the same time the decrease of the turnover of the non-food consumer

\section{Introduction}

Efficient Consumer Response (ECR) Principles and Their Application in Retail Trade Enterprises in Latvia

Submitted 04/2015

Accepted for publication 07/2015

\section{Abstract}

\section{ktu}

European Integration Studies No. 9 / 2015

pp. $257-264$

DOI 10.5755/j01.eis.0.9.12812 (c) Kaunas University of Technology 
goods was $31.4 \%$. In order to explain such decrease many different factors should be taken into account, but primary factor was the stoppage of the issuing of consumption credits.

When the economic situation in the country became stable, the retail trade sector started to bounce back. The sector of the retail trade beginning already with 2011 has been developing like the rest of industry. In 2011 the turnover of the retail trade increased by 4,6\% in comparison with 2010. Especially rapid increase was in the sphere of the non-food consumer good trade (excluding fuel) $-12 \%$; the trade volume of the food products increased by $1,3 \%$, but the retail turnover of fuel decreased by $8,8 \%$. The growth was detected also during the last year. In comparison with the year of 2013 in 2014 the turnover of the retail trade according to comparable data has grown by 3,6\% (data by the Central Statistics Board). We cannot deny the fact that although the retail trade sector directly depends on the domestic situation, the rather negative external environment influences it also. The conflict between Russia and the Ukraine and the related sanctions, as well as the slow development in the European Union have negative impact on the consumers' frame of mind and create motivation to accumulate savings for the possible "hard times", thus slowing down the total consumption. The good news is that, the actual data on labor market and salaries allow to conclude that the internal course of events can still resist the negative external influence (www.csb.gov.lv).

Despite the overall positive rate of retail trade growth, the competition within limits of the industry becomes more intensive. Therefore, it is very important to find ways how to survive and develop successfully in these conditions. The consumer is the one who makes choice and satisfaction of his needs is the primary task of the retail trade. The basis of the consumer's choice is a product (assortment and quality), price and place. The consumer also wishes to receive the according service and all necessary information. In the contemporary age of information consumer can easily obtain the information about the best offer, therefore retail trade enterprises should find possibilities to be leaders in the struggle for the client and to form long-term relationship with him. One of the systems to ensure the effectiveness of the retail trade operations is the ECR. The American marketing management company has found that the gain from the ECR would be $10,8 \%$ in the retail prices (Kurt Salmon Associates 1993). It is expected that the manufacturers would receive $54 \%$ of these savings, whereas the distributers and the retailers would have the rest 46\% (ECR Europe 1997).

ECR - Efficient Consumer Response (understood also as „, quick reaction to consumers' needs”) is cooperation of trade and manufacturing institutions, in order to adapt the sector of the fast moving consumer goods to consumers' needs and to diminish the unnecessary expenditure related to the supply chains. The goal of the ECR is the cooperation to satisfy consumers' needs faster, better and with smaller expenditure. The ECR movement became popular in the mid1990-ies; the reason for this was necessity to look for new solutions in managing distribution channels with an aim to supply consumers faster, qualitative and cheaper by cooperating with the trade partners. Trust among all parties involved is the essential precondition for reaching results (Dyer, Jeffrey $\mathrm{H}$. and Harbir Singh 1998). ECR relation is the long-term relation with the specific input since most likely the partners would start the implementation of the ECR in rather different periods. The partnership presupposes the monitoring and solving all problems together. Nevertheless, if there is a common goal and common understanding, it is possible to reach the goal through joint learning (Teece, Pisano, and Shuen 1997).

The basis of formation of the ECR was the rapid development of information technologies, the ever growing competition, the formation and development of international trade organizations, as well as consumers' need for more qualitative, safer, fresher product with better service and broad assortment (Kato and others 2012). 
The ECR is divided in four zones that are interrelated (see figure 1).

The ECR is the business activity of the whole demand chain; it is reflected in 13 conceptions of improvement that are divided into four ECR spheres - demand management, supply management, suitable technologies and integrating technologies (Busonera, Martini, Zavattini, Santona 2014). The main benefits from the ECR are:

_ Fast reaction to the consumers' needs

_Elimination of losses in the supply chain and decrease of expenses

Increase in the product availability and higher level of customers' service

_ More effective stock management _ Higher service and product level Consumer's benefits from the ECR:

_ Larger choice and shopping according to needs

_ Decrease in shortage of products

_ Fresher and cheaper products

Retailer's benefits from the ECR:

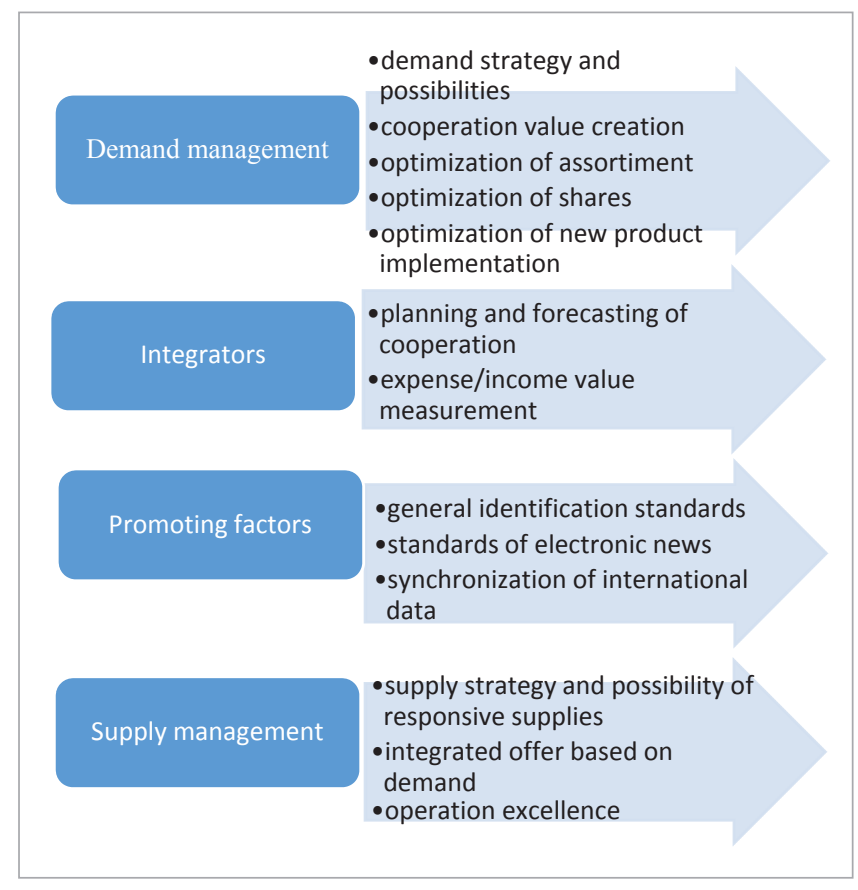

Figure 1

ECR zones

_ Higher consumers' trust and satisfaction

Manufacturer's benefits from the ECR:

- Better market research

_ Better relationship with suppliers

_ Improvement of the chain effectiveness

_ Effective manufacturing

_ Synchronizing of demand

_ Less possibility of the lack of products

_ Stronger positions of the product brand

_ Long-term trade relations (ECR Baltic 2011)

The retailer benefits from the ECR is immense, because the satisfied consumer will return, this will allow the enterprise to save and to reach its goals. What is consumer satisfaction? There are several answers to this question. The most theoreticians ascribe it to satisfactions. H. K. Hunt defines satisfaction in the following way: ".. evaluation expressed by the consumer meaning that the experience of consumption was at least as good as expected" (Hunt 1977). Since the consumer goes to the shop to buy something necessary, then in the case of successful interaction it is possible to make .conclusions about his satisfaction. Summing up, we can say that first of all the consumer in the shop will look for the assortment that corresponds to his needs. This mean that the retail trade is based on providing the assortment that corresponds to the consumer's needs and on the fast reaction to the changes in these needs.

The ECR presupposes to start the assortment formation with the product category management. The product category management views the assortment not as a body of separate products, but instead it divided this body into categories according to consumers' needs and psychological aspects of product purchase. Every retail trade enterprise works out its product categories based on con- 
sumers' needs (Hofstetter 2006). Therefore, it is necessary to start with the consumer research and segmentation, in order to understand in what categories does he think and how does he view the particular shop. In sum, we can say, that the principles of the product category management are:

_ The orientation to the consumer _ _ The relationship based on cooperation

_ The joint systemic approach

_ The continuous improvement.

_ Relying on the data

Figure 2

Product category management process (Dirk, Seifert 2001)

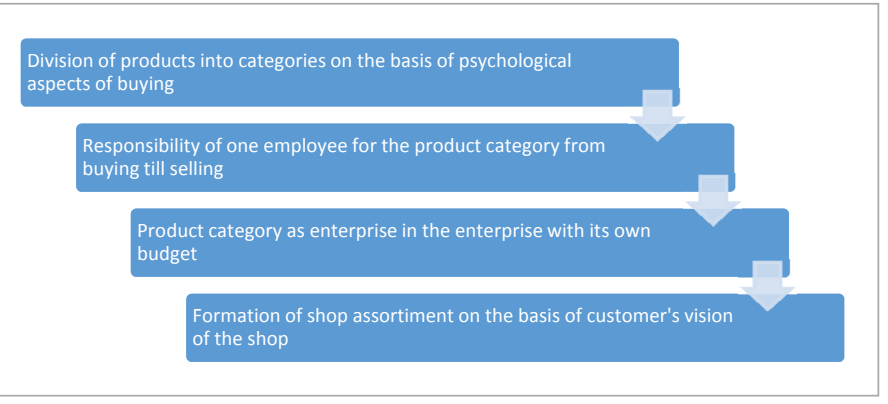

In order to better coordinate these processes, it would be advisable to appoint one person as a product category manager.

Researching all responsibility zones of the product category manager, we can say, that they are related to:

- Cooperation with the suppliers and logistics

- Prices

- Purchase volume and assortment

_ Application of the non-liquides

_ Product placement on the shelves

_ Responsibility for sales results

POS materials placement and sales promotion

Taking into account everything mentioned above, we can say that the product category management is seriously advantageous for the enterprise:

1 The assortment management is planned and the competitiveness of the enterprise increases.

2 The organizational structure of the enterprise becomes optimal and mutual relations improve.

3 All processes are regulated; this ensures interchangeability of the manager.

4 Increase of the consumers' satisfaction and the number of impulse buys is higher.

The assortment is more balanced and harmonious.

5 The sales profit grows. The volume of non-liquids decreases.

6 The relationship with suppliers improve, because there is joint planning of purchase, logistics and promotion activities.

7 Contradictions between purchase and sale disappear.

The implementation of the product category management by itself does not automatically create advantages. We can speak about advantages only when there is revision of the enterprise development strategy, the structure of the assortment, as well as setting the goals for the product category managers and cooperation among all departments (Dirk 2001).

In order to implement the product category management it is necessary to answer these questions: 1 Is there an understanding what the product category management is and why it is necessary?

2 What are the goals of the enterprise?

It is possible to say that the implementation of the product category management requires the detailed business plan, definition of the operative and financial goals, defining the zones of responsibility, setting up deadlines for actions to be taken, as well as working out criteria for evaluation of the plan implementation (Сысоева С.В., Бузукова Е.А. 2013). 
There are many significant benefits from the product category management but how responsive to the implementation of these principles are the retail traders in Latvia? In order to research the situation in Latvia and to determine problems of implementations, we carried out the expert interview with the ECR Baltic director Edgars Pantjuss. Apart from that in cooperation with the Latvian Traders' Association, we surveyed the leading specialists of the Latvian retail trade enterprises.

In 2007 the ECR Baltic the category management work group was created, its task was to educate the Baltic retail trade market about the product category management, to facilitate its introduction into practice; as well as to share experience, to prepare publications and training programs related to the category management.

In his interview, E. Panjuss admitted that there are many problems in the implementation of the ECR principles in the retail trade enterprises in Latvia. The main problems he mentioned were the following:

1 The inability of the retailers to perceive the suppliers as partners and sharing of information.

2 The problem with the precision of product supply.

Using the database of the Latvian Trade Association the survey was carried out among the retail trade enterprises. The research results gave an overview of the real situation in the retail trade enterprises related to the implementation of the product category management; as well as the survey allowed to define the main reasons for its non-implementation. One of the obstacles is the lack of the strategic planning. Summarizing the survey data, we can conclude that $69 \%$ of the retail trade enterprises in Latvia do not have strategic plans, $24 \%$ admit that they have plans for 1-2 years, but only $7 \%$ for a longer period.

The survey demonstrated also the lack of change something in the assortment formation. Although the majority of the enterprises want to change the situation, (see the figure 4).

The lack of understanding of the product category management can be an obstacle in its implementation. Only $14 \%$ of the surveyed enterprises had the full understanding, what does the product category management mean and how the implementation would be possible, $40 \%$ exhibited partial understanding, but 32\% demonstrated only superficial understanding of the processes related to the product category management.
3 The problems with modern technology and use of programs.

4 The resistance of the personnel and the lack of specialists.
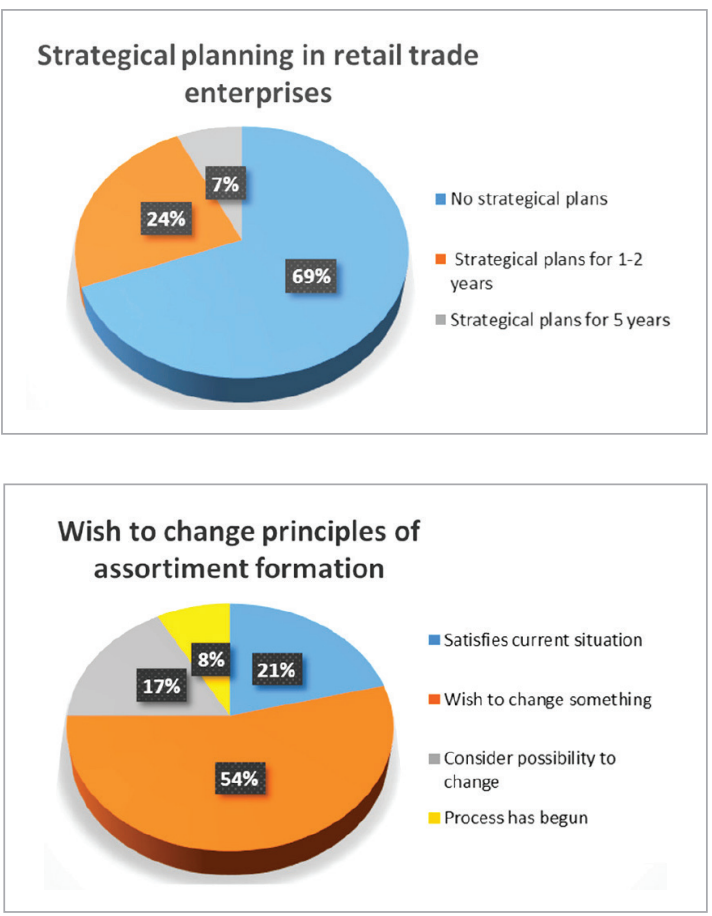

Understanding of product category management

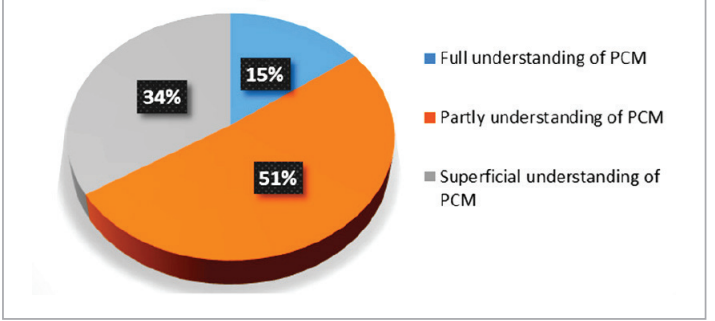

\section{ECR on Retail Trade Enterprises in Latvia}

Figure 3

Strategic planning in retail trade enterprises in Latvia

\section{Figure 4}

Retail trade enterprises' wish to change the principles of assortment formation

\section{Figure 5}

Latvian retail traders' understanding of the product category management 
Summing up all results of the survey, it is possible to conclude the retail traders in Latvia do not recognize and do not appreciate benefits they can gain from the ECR and introduction of the product category management in the enterprise. There, in Latvia has not been carried out the comprehensive research about the benefits from the introduction of the product category management principles because due to the high competition enterprises do not want to share their data. In the European countries (like Switzerland and Austria), where the product category management has been fully implemented, the calculated gain comprises about $30 \%$ of the turnover increase.

Conclusions

The ECR is the business management process that benefits manufacturers, product distributers, traders, and consumers. The ECR presupposes integration of all instruments, in order all parties involved would reach their respective goals. . The product category management is one of the most important components of the ECR. Besides that, it is orientated towards communication with the consumer and planning the changes in consumers' needs. In other words, in order, the products in demand would be in the appropriate place, in the demanded volume and in the right time, as well as in order consumers would be informed. The goal of the ECR rests on four basic principles:

_ Effective assortment

_ Effective price determination
_ Effective product introduction and promotion

_. Effective diversification of assortment.

According to the survey data, we can conclude that $69 \%$ of the retail trade enterprises in Latvia do not have strategic plans, $24 \%$ admit that they have plans for $1-2$ years, but only $7 \%$ for a longer period. Only $14 \%$ of the surveyed enterprises had the full understanding, what does the product category management mean and how the implementation would be possible, $40 \%$ exhibited partial understanding, but $32 \%$ demonstrated only superficial understanding of the processes related to the product category management. The lack of understanding of the product category management can be an obstacle in its implementation. Summing up all results of the survey, it is possible to conclude the retail traders in Latvia do not recognize and do not appreciate benefits they can gain from the ECR and introduction of the product category management in the enterprise.

In order to carry out successfully the product category management in the retail trade enterprise, the authors suggest the following plan of implementation that consists of the following activities:

1 auditing of the existent finances, personnel and other resources;

2 evaluation of the competitiveness and positioning;

3 continuous planning of the business results;

4 preparing the regulating documents for the assortment policies;

5 preparing the regulating documents for the price policy;
6 preparing the regulating documents for cooperation with suppliers;

7 revision the structure and functions of the enterprise;

8 Introduction of the new position - the product category manager, preparing the job description.

The authors offer the model (see figure 6) for the introduction of the ECR in the retail trade enterprises in Latvia. Taking into account the real situation, we suggest to divide the implementation of the ECR into stages and assign the specific time frame for each of these stages. The division into periods will allow to weaken the resistance and will require smaller immediate investments, both financial and in personnel development. 


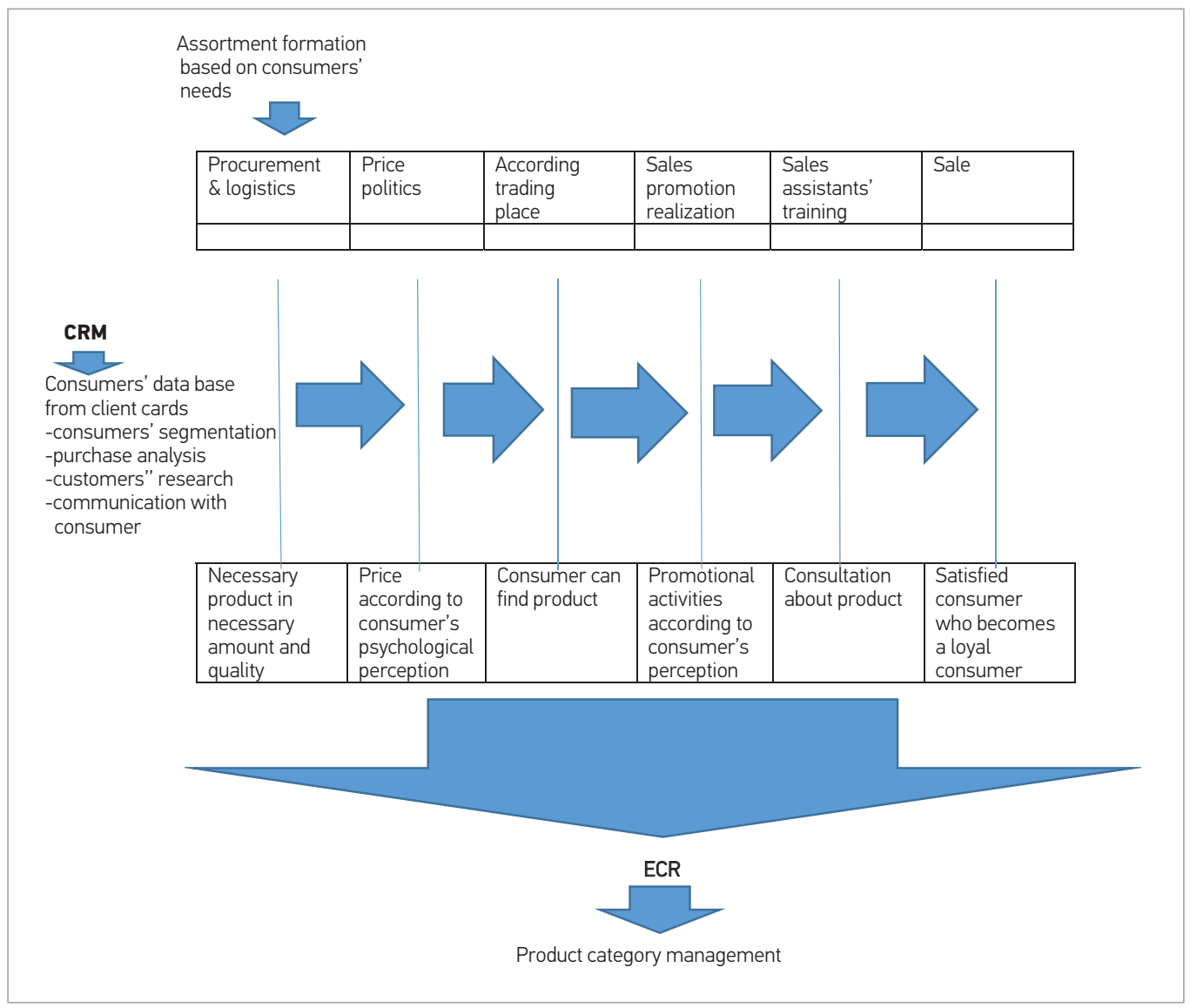

Figure 6

ECR model in retail trade enterprise
Busonera A., Martini P. S.; Zavattini G. C.; Santona A. Psychometric properties of an Italian version of the experiences in close relationships-revised (ECR-R) scale. Source: Psychological Reports. Jun2014, Vol. 114 Issue 3, p785-801. 17p. ISSN: 0033-2941

Dirk Seifert (2001) Efficient Consumer Response. Hampp, Mering,

Dyer, Jeffrey H. and Harbir Singh (1998), "The Relational View: Cooperative Strategy and Sources of Interorganizational Competitive Advantage," Academy of Management Review, 23 (4), 660-79

ECR Europe (1997), Value Chain Analysis. Brussels: ECR Europe (facilitated by PricewaterhouseCoopers).

Hofstetter, Joerg, Assessing the contribution of ECR. Source: ECR Journal. 2006, Vol. 6 Issue 1, p20-29. 10p.

Hunt, H.K. (1977), „CS?D:Overview and Future Research Direction, "// Conceptualization and measurement of Concumer Satifaction and Dissa- faction/ H.Keith Hunt, ed., Cambridge, Ma: MarketingScience Institute

Kato Y.; Kiriyama R.; Takenaka T.; Kurisu Y.; Nozaki D.; Yano K.; Sato F.; lida T. Enhanced production of ECR plasma by using pulse mode microwaves on a large bore ECRIS with permanent magnets. Source: 19. international conference on ion implantation technology, Valladolid (Spain), 25-29 Jun 2012, ISSN: 0094-243X

Kurt Salmon Associates (1993), Efficient Consumer Response-Enhancing Consumer Value in the Grocery Industry. Washington, DC: Food Marketing Institute

Teece, David J., Gary Pisano, and Amy Shuen (1997), "Dynamic Capabilities and Strategic Management," Strategic Management Journal, 18 (7), 509-533.

http://www.em.gov.lv/em/2nd/?cat=30405 (01.03.2015)

http://www.ecr-baltic.org/en/ ( 08.03.2015) 
(http://globalscorecard.gs1.org/gsclive/getting_ started/introduction.asp) (01.03.2015) http://dx.doi. org/10.1002/(SICl)1097-0266(199708)18:7<509::AIDSMJ882>3.0.CO;2-Z
Сысоева С.В., Бузукова Е.А. (2013), Управление асортиментом в розницею Категорный менеджмент. - СПб.: Питер, 288 с, ISBN 978-5459-00774-9

\section{About the \\ ROSITA ZVIRGZDIṆA \\ Business University Turiba \\ Address \\ Graudu 68, Riga LV 1058, Latvia \\ E-mail: rosita@turiba.lv \\ IVETA LININ̦A \\ Business University Turiba \\ Address \\ Graudu 68, Riga LV 1058, Latvia \\ E-mail: iveta.linina@turiba.lv}

\section{VELGA VĒVERE}

The University College of Economics and Culture

Address

Lomonosova 1, corp. 5, Riga LV 1019, Latvia

E-mail:velga.vevere@gmail. com 